\title{
Knowledge, availability and utilization of growth monitoring facilities in urban and rural health facilities in Enugu State, South East Nigeria: A survey of nursing mothers
}

\author{
Ngozi Praise Ezeala-Adikaibe,,${ }^{1,2}$ Joy Eze, ${ }^{3}$ Obumneme Benaiah Ezeanosike, ${ }^{4}$ Adaeze Ayuk, ${ }^{3}$ \\ Birinus Ezeala-Adikaibe 5 \\ ${ }^{1}$ Health Visiting Unit, Department of Community Medicine University of Nigeria Teaching Hospital Enugu, \\ Enugu; ${ }^{2}$ Department of Public Health Education Enugu State University of Science and Technology Agbani \\ Enugu, Enugu; ${ }^{3}$ Department of Pediatrics University of Nigeria Teaching Hospital Enugu, Enugu; ${ }^{4}$ Alex \\ Ekwueme Federal University Teaching Hospital, Abakaliki, Ebonyi State; ${ }^{5}$ Department of Medicine, \\ University of Nigeria, Enugu, Nigeria
}

\begin{abstract}
Sub Saharan Africa (SSA) has one of the highest rates of child mortality compared to the rest of the world's regions. The usefulness of growth monitoring cuts across all areas of pediatric care and remains the pivot for prevention of childhood diseases and prevention untoward mortality. This study therefore aimed at determining the availability of growth monitoring facilities, and
\end{abstract}

Correspondence: Ezeala-Adikaibe Ngozi Praise, Health Visiting Unit, Department of Community Medicine University of Nigeria Teaching Hospital Enugu, Nigeria. P.M.B 01129, Enugu.

Tel.: 08056435102

E-mail: birinusadikaibe@gmail.com

Key words: Growth monitoring, health centers, health centers, Enugu, Nigeria.

Conflict of interest: The authors have no conflict of interest to declare.

Availability of data and materials: All data generated or analyzed during this study are included in this published article.

Ethics approval and consent to participate: The Ethics Committee of Enugu State University of Science and Technology Agbani approved this study. The study is conformed with the Helsinki Declaration of 1964 , as revised in 2013, concerning human and animal rights. All patients participating in this study signed a written informed consent form for participating in this study.

Informed consent: Written informed consent was obtained from mothers who participated in the published in this article.

Received for publication: 14 July 2021.

Revision received: 21 August 2021

Accepted for publication: 21 August 2021.

This work is licensed under a Creative Commons Attribution NonCommercial 4.0 License (CC BY-NC 4.0).

${ }^{\circ}$ Copyright: the Author(s),2020

Licensee PAGEPress, Italy

Annals of Clinical and Biomedical Research 2021; 2:155

doi:10.4081/acbr.2021.155 knowledge and utilization of such facilities among mothers attending rural and urban health facilities in Enugu state. This was a cross sectional descriptive survey of mothers done in selected urban and rural government health facilities using the multi-stage sampling method. Data obtained were analyzed using SPSS version 21.0. Conclusions were drawn at a level of significance, $\mathrm{p}<0.05$ at $95 \%$ Confidence interval. A total of 440 mothers were recruited for the study; 330 (75\%) were from urban and 110 (25\%) from rural locations. Mothers in urban centers exhibited higher knowledge $(84 \%$, VHL) of growth monitoring facilities than those in rural areas, $p=0.04$. Growth monitoring facilities were more available in urban areas compared to rural areas, $\mathrm{p}<0.01$. However, growth monitoring facilities were more utilized by mothers in rural areas than in urban locations. Although GM facilities were more available in urban health centers in Enugu state. These facilities were less utilized especially in the urban areas even though mothers demonstrated were very knowledge about these facilities.

\section{Introduction}

Sub Saharan Africa (SSA) has the highest rates of child mortality compared to the rest of the world's regions. The index of child mortality in the region has remained persistently poor for decades. Every year, about 2.8 million under-5 deaths occur in SSA. In 2019, the region had an average under-five mortality rate of 76 deaths per 1,000 live births. That is equivalent to 1 child in 13 dying before reaching age 5. This rate is two decades behind the world average, which achieved a 1 in 13 rate by $1999 .{ }^{1}$ In Nigeria, under-5 (U5) mortality rate vary widely between regions but remains unacceptably high. Studies in Nigeria have reported varying rates of childhood mortality with sharp differences between rural and urban centers in the country. ${ }^{2,3}$ More than $77 \%$ of under5 deaths are due to preventable and treatable childhood infections. ${ }^{3,4}$

Although the major causes of childhood deaths have been attributed to infections, malnutrition remains an important underlying cause or risk factor for infection in children. The usefulness of growth monitoring cuts across all areas of pediatric care and remains the pivot for prevention of malnutrition in children. Poor growth may be the earliest manifestation of malnutrition, chronic infections as well as endocrine and metabolic disorders in children. ${ }^{5-9}$ Growth Monitoring (GM) therefore, is an effective, simple, and inexpensive way of preventing most childhood malnutrition and illnesses. Growth monitoring involves regular weighing 
and measurement of height and other growth parameters in children and comparing them to standard charts. ${ }^{11,12}$

Effective growth monitoring requires that measurements must be accurately taken using reliable equipment and correct measuring techniques; and subsequently recorded in the growth charts. The technique is simple to perform by mothers irrespective of age and level of education. Thus, it represents a low cost and highly effective way of detecting growth faltering in children and preventing U5 mortality due to malnutrition. Some studies have evaluated the knowledge, and utilization of growth monitoring facilities among mothers. 9,10 These studies have also evaluated the availability of facilities for monitoring growth in health facilities. The availability, knowledge and utilization of these facilities vary widely both within and between countries and tend to be higher in urban compared to rural areas. ${ }^{6,11-16}$

The current study is aimed at determining the availability of growth monitoring facilities, and knowledge and utilization of such facilities among mothers attending rural and urban health facilities in Enugu state, Nigeria. Findings from this study would benefit public health educators, and policy makers in developing targeted public health programs and equitable distribution of resources in the state.

\section{Materials and Methods}

\section{Design of the study}

This was a descriptive survey done in which facilities and respondents (mothers) who sought health services from facilities in Enugu State were selected using the multi-stage sampling method.

\section{Study site}

Enugu State is geographically located in the South-East zone of Nigeria. It has boundaries with Ebonyi State in the East, Anambra State in the West, Benue and Kogi State in the North, Abia and Imo States in the South. Enugu State has seven health districts, viz. Enugu, Awgu, Agbani, Isiuzo, Nsukka, Udi and Enugu-Ezike. ${ }^{17}$ These health districts were stratified into urban and rural location based on the States health system, hence Enugu and Nsukka were under urban while Awgu, Agbani, Isiuzo, Udi and Enugu-Ezike were under rural locations.

\section{Study population}

The respondents for the study were drawn from a population of 133,428 mothers that attended 251 (two hundred and fifty one) health facilities, viz. primary health care centers, secondary and tertiary health facilities spread over the seven health districts in Enugu State from January to July $2016 .{ }^{17}$

\section{Sample size calculation and sampling techniques}

A sample size of 440 mothers (330 from urban location and 110 from rural location) was used for the study; this was based on the number of women registered at each health center. The sample size was determined using Taro Yamane ${ }^{18}$ formula $\mathrm{n}=\mathrm{N} / 1+\mathrm{N}(\mathrm{e})^{2}$; where $\mathrm{n}=$ Sample size; $\mathrm{N}=$ Total population; and $\mathrm{e}=$ Level of significance (0.05).

A multi-stage sampling procedure was adopted to select the needed sample from each of the health districts of Enugu State. Using stratified sampling technique, $40 \%$ of health facilities from the sampled health districts were drawn and $40 \%$ of the populations was sampled. ${ }^{19}$ Seventy four health facilities were selected using balloting with replacement from Enugu, Nsukka, Awgu and
Udi health districts were sampled. Proportionate sampling technique was then used to determine the number of respondents that will be selected from the health districts. Finally, convenience sampling technique was used to recruit consenting mothers as they visited health facilities until the required number of respondents were drawn. Women that repeated their visits to the health facilities were recruited only once.

\section{Instrument for data collection}

The instrument for data collection was a structured interviewer-administered questionnaire for assessment of knowledge, availability, and utilization of GM as a Child Survival Strategy (CSS). It consisted of four sections from A to D. Section "A" obtained the biodata of the respondents. Section B comprised of twenty-seven items addressing knowledge of growth monitoring as a child survival strategy, Section $C$ had eighteen items on availability of Growth monitoring tools in the health facilities while section D had fourteen items on utilization of facilities and resources for growth monitoring by mothers.

Correct or incorrect response alternatives were assigned to determine their responses to items on knowledge while a fourpoint response options of 'Very Much Available' (VMA), 'Available' (A), 'Less Available' (LA) and 'Not Available' (NA) were assigned to determine their responses to items on availability; and 'Very Much Utilized' (VMU), 'Utilized' (U), 'Less Utilized' (LU) and 'Not Utilized' (NU) were assigned for items on utilization of growth monitoring facilities. The score was assigned on a Likert Scale; 4 for VMA and VMU respectively, 3 for A and U respectively, 2 for LA and LU respectively, and 1 for NA and NU respectively. The respondents were instructed to tick the options that best matched their opinions on each item.

\section{Validation of the instrument}

To ensure the face validity of the instrument, copies of it as well as the research questions for the study were given to five experts, four in the Department of Health and Physical Education and one expert in the department of Science and Computer Education both in Faculty of Education, Enugu State University of Science and Technology, ESUT.

\section{Reliability of the instrument}

Copies of the structured questionnaire were administered to 30 CBW who visited five health facilities randomly sampled from Agbani health district. The reliability of items on knowledge was determined using Kuder-Richardson 20 (k-R 20) and a reliability index of 0.93 was obtained. The reliability of items on availability and utilization were determined using Cronbach Alpha formula respectively. Reliability indices of 0.9 and 0.7 were obtained for items on availability and utilization.

\section{Methods of data collection}

Seven research assistants who are trained nurses were trained on questionnaire administration. The researcher and the research assistants administered the questionnaire to the women who visited the health facilities and accepted to be part of the study after detailed explanations of the nature of the study were made. Thereafter, the instrument was retrieved for analysis. The duration of the study was six months.

\section{Method of data analysis}

Data obtained were screened, sorted, coded, and entered into a personal computer. Further data cleaning was done prior to analysis. Data was analysed with SPSS version 21.0 (IBM, Chicago 
Illinois). Responses to question 1 were presented as percentages while responses Level of knowledge of growth monitoring was graded as follows; $1-39 \%$ as 'very low level', $40-59 \%$ as 'low level', $60-79 \%$ as 'high level' and $80-100 \%$ as 'very high level'. For availability of growth monitoring facilities, real limit of numbers were used for the scoring: NA 1.00-1.49; LA 1.50-2.49; A 2.50-3.49; and VMA 3.50-4.00. Similarly, real limits of numbers were also used for grading of utilization as follows NU 1.00-1.49; LU 1.50-2.49; U 2.50-3.49; and VMU 3.50-4.00. Conclusions were drawn at a level of significance, $\mathrm{p}<0.05$ at $95 \%$ Confidence interval.

\section{Results}

A total of 440 mothers were recruited for the study; 330 (75\%) were from urban and $110(25 \%)$ from rural locations.

\section{Research question 1}

What is the level of knowledge of GM, possessed by mothers in Enugu State? The distribution of correct and incorrect answers is shown in Table 1.

Out of the five questions posed to find out the level of knowledge of GM, mothers in urban centers had very high levels of knowledge on items 1,2 and $5(95.2 \%, 85.5 \%$ and $85.5 \%)$ and high levels on items 3 and 4 (79.4\% and 75.5\%) while those in rural centers had very high level of knowledge on only one item $(94.5 \%)$. Mothers in urban centers exhibited higher knowledge $(84 \%$, VHL) of GM than those in rural areas (78\%, HL) as shown in Table 1. P-value was 0.04 suggesting that the knowledge of GM possessed by CBW differ based on location.

\section{Research question 2}

What is the extent of availability of GM facilities and equipment in Enugu State? Data answering this research question are contained in Table 2.

The data presented in Table 2 showed that all the facilities and equipment for GM and the items were available to respondents with mean score of 3.1,3.07, and 3.02; in urban areas and 2.61, 2.51 and 2.58 in rural centers. Notwithstanding the mean scores for the individual items, the grand mean scores of 3.1 and 2.51 showed the growth monitoring facilities were available in both urban and rural locations. The calculated p- value of $<0.01$ for the students Ttest of the mean scores of availability of GM facilities implies that the availability of GM facilities differ based on location.

The data presented in Table 3 showed that out of three items posed to find out the utilization of GM facilities and equipment by mothers, respondents in urban centers had less utilization of facilities and equipment as seen in all the items. On the other hand, respondents in urban centers had less utilization of some of the

Table 1. Frequencies and percentage scores of $\mathrm{CBW}$ mothers in urban and rural centers on knowledge of GM.

\begin{tabular}{|c|c|c|c|c|c|c|}
\hline Question & $\begin{array}{l}\text { Correct } \\
\mathrm{N}(\%)\end{array}$ & $\begin{array}{c}\text { Urban } \\
\text { Incorrect } \\
(\%)\end{array}$ & Decision & $\begin{array}{c}\text { Correct } \\
\text { N(\%) }\end{array}$ & $\begin{array}{c}\text { Rural } \\
\text { Incorrect } \\
\mathrm{N}(\%)\end{array}$ & Decision \\
\hline 1. CSS are steps taken to reduce illnesses that affect survival of U5s & $314(95.2)$ & $16(4.8)$ & VHL* & 104(94.5) & $6(5.5)$ & $\mathrm{HL}^{* *}$ \\
\hline 2. GM is a child survival strategy. & $282(85.5)$ & 48(14.5) & VHL & $84(76.4)$ & $26(23.6)$ & HL \\
\hline 3. GM involves measuring the child's weight and height regularly until 18 years & $262(79.4)$ & $68(20.6)$ & HL & $77(70)$ & $33(30)$ & HL \\
\hline 4. There is a GM card. & 249(75.5) & $81(24.5)$ & HL & $77(70)$ & $33(30)$ & HL \\
\hline 5. GM helps to find out illnesses in children. & $282(85.5)$ & $48(15.5)$ & VHL & $86(78.2)$ & $24(21.8)$ & HL \\
\hline Total & 278 & $84(52)$ & VHL & $86(78)$ & $24(22)$ & HL $p=0.04$ \\
\hline
\end{tabular}

*VHL: Very High Level; **HL: High Level.

Table 2. Mean scores of available facilities and equipment for GM in urban and rural areas.

\begin{tabular}{|c|c|c|c|c|}
\hline & \multicolumn{2}{|c|}{ Urban } & \multicolumn{2}{|c|}{ Rural } \\
\hline & Mean(SD ) & Decision & Correct N(\%) & Decision \\
\hline Clinics or health centers for growth monitoring of my children. & $3.1(0.95)$ & $A^{*}$ & $2.61(0.87)$ & A \\
\hline Weighing scale & $3.07(0.95)$ & A & $2.51(0.85)$ & A \\
\hline Measuring tape & $3.07(0.95)$ & A & $2.44(0.89)$ & $\mathrm{LA}^{* *}$ \\
\hline Growth monitoring charts & $3.02(0.96)$ & A & $2.58(0.91)$ & A \\
\hline Grand mean & $3.1(0.05)$ & $\mathrm{A}$ & $2.51(0.01)$ & $\mathrm{Ap}<0.01$ \\
\hline
\end{tabular}

*A: Available; **LA: Less Available.

Table 3. Mean scores of utilization of facilities and equipment for GM in urban and rural areas.

\begin{tabular}{lcccc} 
& & & & Rural \\
& Mean(SD ) & Correct N(\%) & Decision \\
Clinic or health center for growth monitoring services & $2.17(1.24)$ & $\mathrm{LU}^{* *}$ & $2.61(0.87)$ & $\mathrm{U}$ \\
Growth monitoring chart. & $2.11(1.25)$ & $\mathrm{LU}$ & $2.51(0.85)$ & $\mathrm{U}$ \\
\hline Health facilities for management of weight loss. & $2.53(1.06)$ & $\mathrm{LU}$ & $2.44(0.89)$ & $\mathrm{LU}$ \\
Grand mean & $2.3(0.21)$ & $\mathrm{LU}$ & $2.51(0.01)$ & $\mathrm{Up}>0.01$ \\
\hline
\end{tabular}

*U: Utilized; **LU: Less Utilized. 
facilities and equipments for GM as documented in item 3. The grand mean scores of 2.3 and 2.51 showed that rural mothers utilized GM facilities and equipment more than urban women. Therefore, the answer to research question 3 was that facilities and equipment for GM were more utilized by mothers in rural areas than in urban locations

\section{Discussion}

The index study has documented an extremely high level of knowledge of GM facilities in urban and rural health facilities in Enugu state although they were more available in urban areas. The study also documented lower utilization of GM facilities in urban areas compared to rural areas. These findings agree with the report by Okafor et al. ${ }^{20}$ where respondents in urban and rural centers were aware of growth monitoring and respondents had knowledge of GM as a child survival strategy. ${ }^{21}$ Growth monitoring helps in early detection of malnutrition and respondents in this study expressed high knowledge of this fact. It is quite impressive that a greater percentage of mothers to knew the importance of growth monitoring as this will enable them take adequate steps to prevent malnutrition and its complications, a leading causes of U5 $\mathrm{M}^{22,23}$ in their children. Other studies outside the continent have also reported high level of knowledge of growth monitoring. ${ }^{12}$ It is widely known that knowledge, availability, and utilization of any facility are inter-related as knowledge of such facility is likely to increase its utilization where such facility is available. The fact that some mothers lack knowledge of GM is unacceptable, as they would likely not utilize these facilities to the detriment of their children. Therefore, it is expected that mothers should utilize available facilities especially where enabling environment is established and that health workers should increase the awareness of existence of these facilities through the use of available information, education and communication channels.

Findings on the availability of GM facilities and equipment in health facilities is consistent with reports by Bilal et al. ${ }^{23}$ and AlHilfy and $\mathrm{Essa}^{24}$ who noted that GM equipment were available in their respective studies. Availability of these equipment will ensure that GM which is an essential component of health care for all children will be carried out and will invariably help in early detection of nutritional and other health problems. AI-Hilfy and Essa ${ }^{24}$ in Iraq observed that $85.8 \%$ of children were weighed at the registration visits. Bilal and colleagues also reported a high level of knowledge, great extent of availability and practice of GM among mothers although some mothers who possessed the growth chart could not read or understand it. ${ }^{23}$ Other studies have documented varying levels of availability of GM facilities. A previous study in Nigeria by Nwala et al. found that GM facilities were available only in $41.8 \%$ of public and private hospitals surveyed. ${ }^{25}$

The index study also highlighted the dichotomy between knowledge and utilisation of GM in many developing countries. A study in India reported that only $24.8 \%$ of mothers had good knowledge regarding growth charts and $1.9 \%$ mothers used growth chart at home. Although the authors concluded that there was good knowledge of growth chart, the practice was found to be low. ${ }^{12}$ Our study showed overall less utilization of GM facilities and equipment. It has been reported that only $50.4 \%$ of health workers in SSA carried out growth monitoring practices in healthcare facilities and the knowledge of mothers of GM facilities ranged from $53 \%$ to $87.6 \%{ }^{13,21,22,25-27}$ A study in Ghana, indicated that $53 \%$ of the caregivers' had good (high) knowledge in Growth Monitoring and Promotion (GMP) activities, 98\% had good (high) attitudes towards GMP activities and 70\% had good (high) practices in GMP, only $16.2 \%$ of caregivers' children had faltered in growth. ${ }^{27}$ In contrast, another Ghanaian study reported that only $28.5 \%$ out of four hundred mother-child pairs utilized GM practices while $60 \%$ had adequate knowledge of GM practices. ${ }^{28}$

In Calabar Nigeria, most of the mothers had adequate knowledge of CSS including $69.57 \%$ for growth monitoring, However, the actual practice of most of the components of CSS was poor as only $26.7 \%$, practiced growth monitoring. ${ }^{29}$ Most (85.1\%) of their respondents obtained information on CSS from health workers.

These studies just as the index study contrasted with some other studies that documented great extent of utilization of GM facilities and equipment by their respondents. ${ }^{21,23}$ The lower utilization of GM facilities among mothers in the urban areas may be related to the fact that these mothers patronized mainly the private owned facilities where growth monitoring facilities are sometimes unavailable. Where available, the need for continuous monitoring may not be emphasized as is the case with government owned facilities where education of mothers at each clinic visit is a priority. The findings in the index study calls for a change of attitude through enforcement of individual and community health campaigns in both urban and rural areas. The practice could improve if health workers increased their efforts towards awareness creation.

Health education and demonstration of benefits of growth monitoring by use of audio-visual aids during clinic attendance, and counseling of mothers on these benefits and the danger of not practicing them as they visit health facilities for antenatal, postnatal and child health services is advocated.

\section{Limitations}

The index study has some limitations. The study did not investigate the frequency, consistency, and proper utilization of GM facilities. The benefit of GM facilities will be apparent if the mothers' ability to consistently and correctly use the equipment were observed.

\section{Conclusions}

Although GM facilities were available in rural and urban health centers in Enugu state, they were less utilized especially in the urban areas despite the fact that mothers demonstrated were very high knowledge about these facilities. The dissociation between knowledge, availability and utilization demonstrates the need for public educationist to develop varied community and culturally specific approaches in public health education targeted towards mothers to improve the overall child survival and reduce child morbidity and mortality.

\section{References}

1. UN Inter-agency Group for Child Mortality. Report 2020 Levels \& Trends in Childhood Mortality. 2020. https://www.unicef.org/reports/levels-and-trends-child-mortality-report-2020

2. Adimora GN, Odetunde IO. Perinatal mortality in University of Nigeria Teaching Hospital (UNTH) Enugu at the end of the last millennium. Niger J Clin Pract 2007;10:19-23.

3. Edelu B, Eze J, Oguonu T, Ndu U. (2014). Morbidity and mortality pattern in the children emergency unit of University of Nigeria Teaching Hospital Enugu. Orient J Med 2014;20:3-4. 
4. Mouneke UV, Ibekwe RC, Eke CB, et al. Mortality among paediatric inpatients in Mile 4 Mission hospital Abakaliki, south-eastern Nigeria: a retrospective study. Niger J Paed 2013;40:259-63.

5. Garner P, Pappa R, R. Loge S. Is growth monitoring effective: a systematic review of trials. Arch Dis Child 2000;82:197-201.

6. Akanbi FOM, Anyarsor C. Growth monitoring: the key to child survival strategy in Nigeria. J Res Nurs Midwifery 2014;3:31-8.

7. Khadilkar VV, Khadilkar AV, Choudhury P, et al. Growth monitoring guidelines for children from birth to 18 years. Ind Pediatr 2007;4:187-97.

8. A health professional's guide for using the new WHO growth charts. Paediatr Child Health 2010;15:84-98.

9. Habimana P, Mwinga K, Sagoe MC, Ketsela T. Progress in implementing the child survival strategies in the African region. Afri Health Monit 2010;11:18-23.

10. Sanusi RA, Gbadamosi AO. Mothers' knowledge and practice of child survival strategies. Pak J Nutri 2015;8:1506-11.

11. Efe SI. Health care problem and management in Nigeria. J Geogr Reg Plan 2013;6:244-54.

12. Lavangare SR, Ravichandran P. Knowledge and practice of growth chart among mothers attending Well-Baby Clinic at Urban Health Training Centre, Mumbai, Maharashtra. Ann Comm Health 2020;8:1-5.

13. Bukari M, Abubakari MM, Majeed M, et al. Effect of maternal growth monitoring knowledge on stunting, wasting and underweight among children 0-18 months in Tamale metropolis of Ghana. BMC Res Notes 2020;13:45.

14. Ruger JP, Kim HJ. Global health inequalities: an international comparison. J Epidemiol Community Health 2006;60:928-36.

15. Akanbi FOM, Anyarsor C. Growth monitoring the key to child survival strategies in Nigeria. J Res Nur Midwif 2014;3:31-8.

16. United Nations Children's Fund. The State of the World's Children 2012. New York. UNICEF 2012.

17. Enugu State Government. District Health Law of Enugu State. Enugu State Government 2005.

18. Cochran WG. Sampling Techniques, 2nd Ed., New York: John Wiley and Sons, Inc: 1963.

19. Portney LG, Watkins MP. Foundations of clinical research. USA. Pearson International Edition: 2009.
20. Okafor IP, Dolapo DC, Onigbogi MO, Iloabuchi IG. Ruralurban disparities in maternal immunization knowledge and childhood health-seeking behavior in Nigeria: a mixed method study. Afr Health Sci 2014;14:339-47.

21. Melkamu AW, Bitew BD, Muhammad EA, Hunegnaw MT. Prevalence of growth monitoring practice and its associated factors at public health facilities of North Gondar zone, northwest Ethiopia: an institution-based mixed study. BMC Ped 2019;19:144

22. Debuo DT, Appiah PK, Kweku M, et al. Caregivers knowledge, attitude and practices on child growth monitoring and promotion activities in Lawra District, upper west region of Ghana. Sci J Pub Health 2017;5:20-30.

23. Bilal SM, Moser A, Blanco R, et al. Practices and challenges of growth monitoring and promotion in Ethiopia. J Health Popul Nutr 2014;32:441-51.

24. Al-Hilfy TKY, Essa A. Mothers' knowledge and attitude regarding childhood survival. Mid E J Fam Med 2007;5:1279.

25. Nwala E, Ebunoha, G, Ugwu, C. Mothers knowledge of available child health services in Ezeagu, Enugu. Bmc Health Serv Res 2013;2:7.

26. Yidana A, Ziem JB, Seidu F, Mogre V. Utilization of growth monitoring and promotion is highest among children aged 0 11 months: a survey among mother-child pairs from rural northern Ghana. BMC Public Health 2021;21:910

27. Daniel B, Tesfaye N, Mekonin E, et al. Knowledge and attitude on growth monitoring and its associated factors among mothers/guardians of children less than two years in Areka Town, Southern Ethiopia. J Nutr Disorders Ther 2017;7:216.

28. Edet YV, Effiong JH, Udoh IA, et al. Knowledge and practice of child survival strategies among mothers attending postnatal clinic in Itu, a sub-urban area of South Nigeria. Int J Health Sci Res 2020;10:1-8.

29. Etokidem AJ, Johnson O. Child survival strategies: assessment of knowledge and practice of rural women of reproductive age in cross River State, Nigeria J Trop Med 2016;5098463. 